\title{
The wild tomato species Solanum chilense shows variation in pathogen resistance between geographically distinct populations
}

\author{
Remco Stam ${ }^{\text {Corresp., }}{ }^{1}$, Daniela Scheikl ${ }^{1}$, Aurélien Tellier ${ }^{1}$ \\ ${ }^{1}$ Section of Population Genetics, Technical University of Munich, Freising, Germany \\ Corresponding Author: Remco Stam \\ Email address: stam@wzw.tum.de
}

Wild tomatoes are a valuable source of disease resistance germplasm for tomato (Solanum lycopersicum) breeders. Many species are known to possess a certain degree of resistance against certain pathogens, however evolution of resistance traits is yet poorly understood. For some species, like Solanum chilense, both differences in habitat and within species genetic diversity is very large. Here we aim to investigate the occurrence of spatially heterogeneous coevolutionary pressures between populations of S. chilense. We investigate the phenotypic differences in disease resistance within $S$. chilense against three common tomato pathogens (Alternaria solani, Phytophthora infestans and a Fusarium sp.) and confirm high degrees of variability in resistance properties between selected populations. Using generalised linear mixed models, we show that disease resistance does not follow the known demographic patterns of the species. Models with up to five available climatic and geographic variables are required to best describe resistance differences, confirming the complexity of factors involved in local resistance variation. We confirm that within $S$. chilense, resistance properties against various pathogens show a mosaic pattern and do not follow environmental patterns, indicating the strength of local pathogen pressures. Our study can form the basis for further investigations of the genetic traits involved. 
1

2 The wild tomato species Solanum chilense shows variation in pathogen

3 resistance between geographically distinct populations

4

5 Remco Stam*, Daniela Scheikl, Aurélien Tellier

6 Section of Population Genetics, Technische Universität München, Liesel-Beckmann

7 Strasse 2, 85354 Freising, Germany

$8 \quad{ }^{*}$ Author for Correspondence: Remco Stam: stam@wzw.tum.de 


\section{Abstract}

16 Wild tomatoes are a valuable source of disease resistance germplasm for tomato

17 (Solanum lycopersicum) breeders. Many species are known to possess a certain degree of pathogen resistance against certain pathogens, however evolution of resistance traits is yet poorly understood. For some species, like $S$. chilense, both differences in habitat between populations and within species genetic diversity are very

21 large. Here we aim to investigate the occurrence of spatially heterogeneous (co-

22 )evolutionary pressures between populations of S. chilense.

23 We investigate the phenotypic differences in disease resistance within wild tomato

24 species S. chilense against three common tomato pathogens (Alternaria solani, 25 Phytophthora infestans and Fusarium sp.) and confirm high degrees of variability in 26 resistance properties between selected populations. Using generalised linear mixed 27 models, we show that disease resistance does not follow the known demographic 28 patterns of the species. Models with up to five available climatic and geographic 29 variables are required to best describe resistance differences, confirming the complexity 30 of factors involved in local resistance variation.

31 We confirm that within S. chilense, resistance properties against various pathogens

32 show a mosaic pattern and do not follow environmental patterns, indicating the possible

33 strength of local pathogen pressures. Our study can form the basis for further

34 investigations of the genetic traits involved. 


\section{Introduction}

In nature, plants are exposed to a wide range of pathogens and pests. While in most cases the plants appear non-specifically resistant against these threats, drastic or recurrent epidemics do occur (Thrall, Burdon \& Bock, 2001; Soubeyrand et al., 2009) and variability in specific resistance to pathogens is observed (Thrall, Burdon \& Young, 2001; Salvaudon, Giraud \& Shykoff, 2008). Understanding how reciprocal co-adaptation of hosts and pathogens maintains such diversity has been a key question in theoretical and empirical evolutionary biology. Theoretically, negative direct frequency-dependent selection (ndFDS) is shown to be a necessary condition to maintain long-term stable diversity for resistance in plants and infectivity in pathogens (Tellier \& Brown, 2007). Seed banking, perenniality or polycyclic disease can generate ndFDS, while costs of resistance and infectivity (virulence) are necessary but not sufficient for stable long term polymorphism to occur (Tellier \& Brown, 2009; Brown \& Tellier, 2011). Another factor often suggested to maintain diversity is the spatial structure of host and pathogen populations. Spatial structure and migration of hosts and pathogens as well as population sizes and genetic drift generate patterns of local adaptation over space and time (Thrall \& Burdon, 2002; Gandon \& Michalakis, 2002). However, a spatial structure with homogeneous environment does not generate ndFDS (Thrall, Burdon \& Bever, 2002; Tellier \& Brown, 2011). Stable long term polymorphism is favoured by spatially heterogeneous environments across which the prevalence and severity of disease or the costs of resistance and infectivity may differ (Gavrilets \& Michalakis, 2008; MorenoGamez, Stephan \& Tellier, 2013). 
59 From an ecological perspective, and based on the classic disease triangle from plant

60 pathology (Agrios, 2005) the outcome of species interactions are mediated by the

61 abiotic and biotic environment. The influence of the environment therefore generates

62 spatial and temporal variation in evolutionary and coevolutionary dynamics (Thompson,

63 2005), and increasing evidence for geographical variation in coevolutionary dynamics

64 and patterns of local adaptation are found in microcosm experiments (Forde, Thompson

65 \& Bohannan, 2004; Vogwill et al., 2009; Lopez-Pascua, Brockhurst \& Buckling, 2010).

66 Nevertheless, few field systems exist to study and document the coevolution of plants

67 and their pathogens occurring at short time scales and across several populations. One

68 example is the wild flax - flax rust pathosystem, where local adaptations have been

69 observed and the most resistant varieties of flax generally harboured more virulent

70 strains of rust (Thrall, Burdon \& Bever, 2002; Thrall \& Burdon, 2003). Similarly, the local

71 adaptation of powdery mildew Podosphaera plantaginis to Plantago lanceolata

72 populations spread over different islands off the coast of Sweden showed virulent

73 strains to co-occur with more resistant plants (Laine, 2005; Soubeyrand et al., 2009). In

74 the latter plant-pathogen system, severaltheoretically proposed mechanisms to

75 generate ndFDS have been shown to originate from the environmental heterogeneity

76 across populations: 1) GxGxE interactions (host genotype x pathogen genotype $x$

77 environment, (for example Laine 2006), 2) heterogeneity in disease incidence and

78 prevalence determining epidemiological pressures (Soubeyrand et al., 2009) and co-

79 infection (Susi et al., 2015) and 3) different strength of connectivity between populations

80 accelerating or decelerating the speed of coevolution across the landscape (Jousimo et

81 al., 2014). Thus, these factors are expected to promote and facilitate long term 
82 polymorphism at resistance and infectivity loci without unrealistic costs of these alleles.

83 Here we aim to investigate the variation of disease resistance properties amongst

84 populations of $S$. chilense, a wild tomato species, against several pathogens.

85

86 Wild Solanum species are in general particularly good model species to study between

87 and within species variation, because they occur in diverse geographic and climatic

88 habitats and have a very well studied demography and known evolutionary history

89 (Städler, Roselius \& Stephan, 2005; Städler, Arunyawat \& Stephan, 2008; Tellier et al.,

90 2011). Additionally, several studies exist suggesting that bacterial resistance-associated

91 genes are under selective pressure (Rose et al., 2005, 2011; Rose, Michelmore \&

92 Langley, 2007). S. chilense is native in South America, ranging from southern Peru to

93 central Chile, and colonised a broad range of habitats. S. chilense populations are

94 found from coastal regions, even in slightly alkaline environments, all the way to high

95 altitude (>3000 m) mountain regions. It also occurs in extreme dry habitats on the

96 border of the Atacama dessert, as well as near rivers and creeks (Peralta, Spooner \&

97 Knapp, 2008).

S. chilense most likely originated with its sister species $S$. peruvianum, in south Peru

99 and then migrated south (Städler, Arunyawat \& Stephan, 2008). A study of the species'

100 demography found four genetically distinct groups; one in the north of the range, one in

101 the central region and two in the south (one on the coast and one at high altitudes).

102 Interestingly, the two southern groups are, even though geographically close to each

103 other, more related to the central group than to each other, possibly due to the

104 separating effect of the extremely arid Atacama desert (Böndel et al., 2015). In addition, 
105 S. chilense shows clear climatic adaptations. Populations from drier regions are

106 responding faster to drought (Fischer et al., 2013) and individual populations found at

107 high altitudes (>3000 m) show higher freezing tolerance (Nosenko et al., 2016) S

108 chilense has also been the source of resistance loci against the fungus Verticilium

109 dahliae (Tabaeizadeh et al., 1999) and against various viruses (Griffiths \& Scott, 2001;

110 Ji et al., 2007; Verlaan et al., 2013). Seeing that S. chilense occurs in such a wide range

111 of habitats and that the species shows specific signs of local climatic adaptations, we

112 wondered whether we could find variation for pathogen resistance as well.

113

114 Since no detailed data exist about the co-occurrence of wild pathogens and S. chilense,

115 we chose to test $S$. chilense disease resistance properties with three widely studied and

116 economically relevant pathogens, Alternaria solani, Phytophthora infestans and a

117 Fusarium sp.

118 A. solani causes early blight and is amongst the most destructive diseases of tomato in

119 tropical and subtropical regions, leading to yield losses of up to $80 \%$ in certain regions.

120 A. solani has been found in central Peru and is known to cause disease not only on

121 potato - its main host - but also on many other nightshades, including tomato (Song et

122 al., 2011; Kumar et al., 2013). In addition, previous work has shown that $A$. solani

123 resistance can be studied using detached leaf assays (Chaerani \& Voorrips, 2006;

124 Chaerani et al., 2007).

125 Fusarium spp. are pathogens that cause very severe disease symptoms on a very wide

126 range of host plants that span almost the entire globe (Agrios, 2005). Two Fusarium spp

127 are in the top ten most important fungi in plant pathology (Dean et al., 2012). The $F$. 
128 oxysporium species complex comprises over 100 formae specialis that all infect specific

129 hosts, including tomato (Michielse \& Rep, 2009). The F. oxysporium species complex is

130 widely used to study molecular and genetic mechanisms involved in plant pathogen

131 interactions (Houterman, Cornelissen \& Rep, 2008; Ma, Cornelissen \& Takken, 2013)

132 and even though it is generally reported to be a vascular pathogen, it has regularly been

133 successfully deployed in detached leaf infection assays (e.g. Kavroulakis et al., 2007).

134 Phytophthora infestans is an oomycete that causes late blight on potato and tomato. In

135 potato alone the damage amounts up to $\$ 1$ bn annually (Haverkort et al., 2009). Due to

136 its economic value and the vast amount of molecular and genetic research performed

137 on it, it is considered the most important oomycete plant pathogen (Kamoun et al.,

138 2015). Like the other two pathogens used in this study, P. infestans is known to occur in

139 the geographic range of various wild Solanum species (Perez et al., 2001). Specifically,

140 the strain EC1 that we used here has its origin in Ecuador and is particularly relevant for

141 agriculture as it is a rather aggressive strain that is capable of overcoming certain novel

142 genetic resistances (Foster et al., 2009; Nowicki et al., 2011).

143

144 Here we test the resistance of different S. chilense populations. We selected seven

145 populations that represent three previously described genotype groups from Peru and

146 Chile (Böndel et al., 2015). Two populations originate from the central range (LA1958,

147 LA3111), two from the coastal regions (LA2932, LA4107) and two from the southern 148 mountainous region (LA4117, LA4330). A seventh population is geographically in the

149 middle between the southern mountain and the central group (LA2931). Böndel et al.

150 group it with the central populations, but assign properties of both groups to it. Figure 
151 1A shows the species distribution and highlights the selected populations. These groups

152 correspond to very distinctive habitats and can thus be used to investigate whether we

153 see differences in infection rate throughout the range of the species. We also test

154 whether these differences show a linear pattern when tested against geographical and

155 climatic variables (e.g. corelation between latitute or precipitation and resistance) or

156 whether a multitude of factors leads to specific geographical variations in resistance to

157 each of the three pathogens. Our study will help inform on the occurrence of spatially

158 heterogeneous coevolutionary pressures between the populations of Solanum chilense,

159 a solanaceous wild species, and its pathogens.

160 


\section{Methods}

\section{Plant growth}

163 Seed batches were obtained from the tomato genomics resource centre (TGRC, Davis,

164 USA). We grew seven different Solanum chilense populations (accession numbers

165 LA1963, LA2931, LA2932, LA3111, LA4107, LA4117 and LA4330) consisting of 10

166 different plants each and one Solanum pennellii (LA0716) population in our glasshouse

167 from randomly chosen seeds. The plants were grown with $16 \mathrm{~h}$ light and a minimum

168 temperature of $18^{\circ} \mathrm{C}$. Mature plants were cut back at a biweekly interval to assure

169 young leaves of similar age were available at all times for all populations

171 Pathogen propagation and spore production

172 Alternaria solani

173 A. solani strains B055 and St108 were obtained from the chair of Phytopathology at the

174 TUM (Munich, Germany) (Leiminger et al., 2016). The strain was originally collected

175 from potato, though $A$. solani strains are known to be generalists with strains capable of

176 infection both potato and tomato. A. solani and cultivated on SNA (Salt Nutrient Agar)

177 plates (at $22^{\circ} \mathrm{C}, 12 \mathrm{~h} \mathrm{UV-A} \mathrm{light,} 12 \mathrm{~h}$ darkness and $85 \%$ humidity) for three weeks to

178 induce sporulation. We harvested the spores by submerging the cultures in with $\mathrm{ddH}_{2} \mathrm{O}$

179 and scratching the mycelium off the agar with a microscope slide. The solution was

180 filtered through four layers of mesh (grade 60, approximately $12 \times 12$ threads per $\mathrm{cm}^{2}$ )

181 and diluted to a concentration of 5000 spores per ml. Each leaflet was infected with a

$18210 \mu l$ droplet.

183 Phytophthora infestans 
184 We obtained late blight pathogen $P$. infestans strain EC1 from the James Hutton

185 Institute (Dundee, UK). Although originally obtained from potato, samples belonging to

186 the EC1 lineage have been found on other solaneceous hosts (Vargas et al., 2008). It

187 was cultivated on RyeB agar, incubated six days at RT in darkness, three days at RT in

188 daylight. We scratched the sporangia from the plate with ice cold water using a pipette

189 tip and stored it at $4^{\circ} \mathrm{C}$ until further use (up to three hours). The solution was diluted to

$1902000-3000$ sporangia per $\mathrm{ml}$ and the leaflets were infected with $5 \mu \mathrm{l}$ of this solution.

191 Fusarium sp.

192 Fusarium infected lesions were identified on a few detached S. chilense leaves from our

193 glasshouse. These lesions were extracted and re-cultivated for several rounds on

194 Potato-Dextrose-Agar (PDA) for clean-up. Microscopic observations and sequence

195 analysis of cloned Beta-Tubulin genes from several individual cultures confirmed that

196 the cultures were axenic (Supplemental Data S7). We used BLAST with said Tubulin

197 sequences to search against the fungidb.org database and to confirm the genus. The

198 clean Fusarium was grown on PDA for a minimum of four days at RT. Spores were

199 harvested by adding $d d \mathrm{H}_{2} \mathrm{O}$ and aspirating the liquid. The spores were diluted to $2 \times 10^{5}-$

$2005 \times 10^{5}$ spores per $\mathrm{ml}$ and we infected the individual leaflets with $5 \mu \mathrm{l}$ of this solution.

201 All protocols for pathogen cultivation, including ingredients for the growth media can be

202 found in more detail on https://www.protocols.io/view/Plant-Pathogen-Cultivation-

203 fmkbk4w

204

205 Leaf pre-treatment

206 In some wild tomato species (e.g. S. pennellii), thick and sticky surface coatings have a 
207 dramatic effect on pathogen ingress. In S. chilense, surface coatings are notably less

208 thick, and resemble those of cultivated tomato. However, the selected S. chilense

209 populations have slightly different leaf morphology. Different amounts of wax could be

210 present and could cause differences in infection rates between the populations. We

211 aimed to look at differences in molecular defence rather than physical barriers

212 preventing hyphal ingression. Hence, to minimise the effect of differences in surface

213 coating, we washed the leaves briefly in $70 \%$ ethanol, followed by rinsing with distilled

214 water and a brief drying period before infection. This ethanol treatment has the added

215 effect of surface sterilisation of the leaves, preventing bacterial contamination. The

216 effects of $S$. chilense surface sterilisation and washing off the wax is noticeable during

217 infection, but not as dramatic as with S pennellii (S Data 1).

218

219 Infection assays

220 To assess the infection rate of the different pathogens, we performed spot inoculations

221 on detached leaves. Each spot was scored as either negative (no symptoms or only a

222 small hypersensitive response lesion) or positive (larger (expanding) lesions or full

223 proliferation of the pathogen) (Figure 1B). To minimise the effect of variation between

224 plants within one population, we randomly collected leaves with the same age from

225 eight to ten plants per population and shuffled them. We then drew the leaves from that

$226 \mathrm{mix}$ to distribute them over up to nine boxes for each infection experiment. Each box

227 contained 16 leaves, in four columns with four rows. Each column corresponding to a

228 different population. Each box contained different combinations of populations (Figure

229 1C). Box number and leaf position were marked to later rule out possible effects. For 
230 each pathogen 16-24 leaves - about 100 leaflets - were infected for each population.

231 Over the course of several months, we performed four biological replicates for each

232 population, , accumulating to about $450-500$ infected leafletsper population per

233 pathogen. The Alternaria infections were done on the adaxial side of the leaves,

234 Phytophthora and Fusarium infections were done on the abaxial side of the leaves. The

235 leaves were incubated at RT and scored after six to eight days, dependent seasonal

236 variability of temperature and light conditions in the lab, which slightly affected the rate

237 of symptom development..

238

239 Data analysis

240 All data analysis was done using $R$ (version 3.2.3) ( $R$ foundation for statistical

241 computing). Generalised Linear Mixed Models (GLMM) were made using the glmer

242 option from the package Ime4 (Bates et al., 2015, p. 4). To construct GLMM we used a

243 binomial variable $(y)$ consisting of the number of successful and unsuccessful infection

244 events per leaf. The GLMM were constructed taking the leaf position in the box (leaf)

245 and a combination of the box number and experimental date (exp:box) into account as

246 random effects. For our first model populations names were used as fixed effects.

247 (model1 $=y \sim$ accession $+(1 \mid$ leaf $)+(1 \mid$ exp:box $))$. For the next models, we hierarchically

248 tested different climatic and geographical parameters (e.g. model2 $=\mathrm{y} \sim$ geographic $1+$

249 climatic1 + climatic2 + (1|leaf)+(1|exp:box $))$. Pairwise comparisons were examined

250 using an implementation of Tukey Honest Significant Difference test as provided by

251 function glht from the R package multcomp (Hothorn, Bretz \& Westfall, 2008). glht

252 allows post-hoc hypothesis testing, similar to THSD, but is more suitable for general 
253 linearised (mixed) models. The boxplots were drawn using the package ggplot2

254 (Wickham, 2009, p. 2). All packages are available through CRAN.

255

256 Distribution map and geographical characteristics

257 Geographical data for all populations were obtained from the Tomato Genome

258 Resource Centre. Climatic data were extracted from the http://worldclim.org/ database.

259 The species distribution map was drawn using the maps package (Becker, Minka \&

260 Deckmyn, 2016) in R. All geographic and climate data used can be found in S Data 2.

261

262 Results

263 S. chilense populations show different resistant properties against different 264 pathogens

265 To test infection rates, we infected individual leaflets for up to 16 leaves of each $S$.

266 chilense population with Alternaria solani (st108) and counted the occurrence of

267 infected leaflets per leaf, as this represents the success rate of the pathogen to

268 establish itself and overcome genetic resistance. We scored infection events as either

269 negative (no infection or clear small necrotic lesions, indicating a hypersensitive

270 response) or positive (ranging from growth just outside the droplet area up to full

271 infection of the leaflet) (Fig 1B)(All raw data can be found in S Data 3). We observed

272 variation within each population. In almost all instances at least one leaf was fully

273 infected whereas another was completely resistant. These outliers have large effect on

274 the calculated mean fraction. To allow good judgement we report the $1^{\text {st }}$ and $3^{\text {rd }}$

275 quantile, the median value as well as the mean value for each population (Fig 2). The 
276 mean and median of the infected fractions range from 0.35 and 0.42 for LA3111 to 0.74

277 and 0.81 for LA4330 or 0.67 and 0.82 for LA2932.

278 To test the robustness of our method, we did an additional infection with a second strain

279 of Alternaria (B055). The overall infection rates were lower in this set of experiments

280 (median of 0.54 compared to 0.62 ), however S Data 4 shows that just like for strain

281 st108, LA3111 is the least infected population with a mean of 0.40 and LA4330 and

282 LA2932 have a high median, with an infected fraction of 0.70 or 0.73 respectively.

283 With Fusarium we also saw differences in the infected fraction amongst populations.

284 Interestingly LA3111 was in this case the most infected population (mean: 0.72, median:

285 082) whereas LA4107 was the least susceptible $($ mean $=0.28$, median $=0.11)$.

286 Finally, for $P$ infestans, the infected fractions again showed a different pattern. There

287 was a larger spread of the data as can be seen by the increased distance between the

$2881^{\text {st }}$ and $3^{\text {rd }}$ quartile and the lowest and highest mean and median fraction were closer

289 together, ranging from 0.30 and 0.21 for LA3111 to 0.60 and 0.70 for LA4330 (Fig 2C).

290 LA3111, one population that seemed particularly resistant against Alternaria and

291 Phytophthora seems to be the most susceptible to Fusarium.

292

293 To test the significance of the differences and the effect of the different populations on

294 infection, we constructed a general linearised mixed model (GLMM). We assigned

295 experimental parameters (data, box and leaf number) as random effects and tested

296 whether there were significant differences between the populations for each infecting

297 species by looking at the infection counts (y) per leaf. These models showed that

298 indeed there are highly significant differences $(p<0.00001)$ in infection rates between 
some populations for all three pathogens tested (S Data 2).

300

301 Pairwise comparisons reveal individual differences between different pathogens

302 To further determine which populations were different from each other, we performed

303 pairwise comparisons using a variant of Tukey's Honest Significant Difference test (see

304 methods). The observed pairwise differences were clearly distinct between the three

305 pathogens. Figure 3 shows a summary of the pairwise differences, with corresponding

306 difference estimates for each comparison. Cells with significant differences $(p<0.001)$

307 are highlighted in green. All pairwise differences with their $95 \%$ confidence intervals are

308 plotted in S Data 5. Of the 63 pairwise comparisons, 32 showed a significant difference

309 in infection ratio. Overall, there were more significant differences between populations

310 when it came to Fusarium infection (15) than to Alternaria infection (10) or Phytophthora

311 (7). Interestingly, some populations showed the same result for all pathogens: there are

312 no differences between LA1963 and LA2931 (both central) nor for LA2931 and LA4107

313 (central and south coast) or LA4107 and LA4117 (south coast and south mountain).

314 Also, LA1963 was always more susceptible than LA2932, and LA4117 was always

315 more susceptible than LA4330. In some cases a population in a pair was more resistant

316 to one pathogen and more susceptible to another. LA4330 was more resistant than

317 LA3111 to Fusarium, but less resistant to Alternaria and Phytophthora.

320 A mix of climatic and geographic variables affect pathogen resistance

321 To see whether a change in certain geographic and climatic conditions could be linked 
322 to an increase or decrease of resistance rates between populations, we built new

323 GLMM using such data. First we made a simple model for resistance to Alternaria,

324 testing the infection counts (y) against either latitude or longitude, a combination of both

325 or an interaction of both. This showed that both latitude and longitude had a significant

326 effect $(p<0.001$, Table 1$)$. The quality of the models is reported by the statistical

327 software using the Akaike Information Criterion (AIC), where a lower AIC, indicates a

328 better relative quality of the model. A model with both parameters showed a better AIC.

329 However, a model with an interaction only shows significance of the latitude parameter.

330 We extended the model to include both parameters (longitude + latitude) as well as

331 several environmental parameters. We obtained the best AIC (2641.8) for a model

332 containing altitude, annual precipitation, the temperature in the wettest and the

333 temperature in the coldest quarter. Additions of other climatic data did not yield an

334 improvement of the model. A selection of tested models with their AIC and significance

335 is shown in Table 1 . When closely investigating the best fitting model for resistance to

336 Alternaria (Table 1, model 6), we noted that whereas all variables contribute significantly

337 to the model, the estimated effect size differs greatly. Table 2 shows that of all effects,

338 longitude was the strongest effect, followed by the mean minimum temperature in winter

339 (TempB), the annual precipitation and altitude. It should be noted that models that only

340 take temperature effects into account did not account for significance (Table 1). A

341 GLMM with the infection counts set against the previously identified genetic groups ( $\mathrm{y} \sim$

342 group), yielded a higher and thus worse AIC (2705). The model with the populations

343 yields an as good AIC as the one with six climatic variables. This suggested that no

344 single variable has a strong, exclusive correlation to infection rate and that each 
345 population represented its own micro environment with specific geographic and climate

346 parameters that are all of influence.

347 Similar to resistance to Alternaria, we tested all variables for resistance to Phytophthora

348 and resistance to Fusarium. The pattern seen for resistance to Phytophthora is almost

349 identical to that of Alternaria resistance. The AIC values are generally lower, but the

350 trends are the same. Interestingly, Fusarium resistance showed a different picture.

351 Whereas longitude was still the strongest effect, its effect and significance were lower

352 and the temperature in the coldest quarter of the year had a relatively larger effect. The

353 effect of altitude was not significant and differences in annual precipitation had a nearly

354 negligible effect as well. In fact, a simplified model (Table 1, model 6b) that excludes the

355 insignificant parameters had a better fit. As with resistance to Alternaria, the model

356 testing for the genetic group effect showed a lesser fit than the model per population

357 (results for selected models can be found in S Data 2).

358

359 Discussion

360 The wild tomato Solanum chilense grows in a variety of habitats in Chile and Peru,

361 ranging from lower coastal areas to very high altitudes $(>3000 \mathrm{~m})$. These populations

362 experience considerable variation in geographic parameters like precipitation and

363 temperatures. It is known that $S$. chilense has a clear demographic pattern and signs of

364 adaptations to climatic differences between different populations (Fischer et al., 2011,

365 2013; Nosenko et al., 2016). A demographic pattern of North-South colonisation is

366 observable with larger and more diverse populations in the north of the range and

367 smaller and less diverse populations in the south. In addition, there is little to no genetic 
368 exchange between some of the southern most populations that are separated by the

369 extremely dry Atacama desert. This leads to the conclusion that S. chilense can be

370 divided in a northern, a central and two southern genotype groups (Böndel et al., 2015).

371 We hypothesised that pathogen pressures must differ a lot between such diverse

372 geographical locations and as such S. chilense should show variation in resistance to,

373 common, plant pathogens between the different populations. The underlying

374 assumption is that at the evolutionary time scale of thousands of years, climatic

375 conditions generate different selective pressures and presence/absence of pathogens,

376 which then drives the evolution of the plant immune genes along different evolutionary

377 paths in different regions. This heterogeneity in space may be seen as variation in

378 functionality or duplication of resistance genes (so-called R-genes) and different levels

379 of quantitative resistance across populations depending on pathogen availability and

380 trade-offs for costs of resistance (Moreno-Gamez et al 2013). The result of this

381 evolutionary process was testedby performing infection assays in a common

382 environment to assess the degree of resistance to three Solanum pathogens. We

383 observed clear differences between the infection success rates of the three pathogens

384 on the different $S$. chilense populations, indeed suggesting local adaptations to

385 pathogen pressure. We could only observe a clear separation between three regional $S$.

386 chilense genotype groups for resistance to Alternaria, where the central populations are

387 more susceptible than those from groups in the south. This shows that the genotype

388 groups can be seen as an indicator of resistance against Alternaria. For resistance to

389 the other pathogens large within-group differences exist and the genotype groups

390 cannot be considered an indicator of resistance. Pairwise comparisons confirmed that 
391 outcomes differ within groups and between pathogens. For example, a pair that shows

392 significant differences for resistance to Phytophthora and Alternaria (LA1963-LA4330)

393 does not show differences in infection rate for Fusarium. Very strong pairwise

394 differences can even be seen within the previously identified genotype groups (e.g.

395 LA2932-LA4107 with Fusarium). We also showed that there are no populations that are

396 in general more resistant (e.g. against all pathogens). For example, LA3111 is

397 particularly resistant against Fusarium, but the most susceptible to Phytophthora and

398 Alternaria.

400 We used a GLMM to test which factors might contribute to these differences.

401 Interestingly, whereas the species S. chilense as a whole, shows a strong north-south

402 demography, our analyses show that in models with multiple variables not latitude, but

403 longitude has a very strong effect on infection rates. This could on the one hand be

404 explained by the absence of the northern-most group in our analysis. On the other

405 hand, a more likely explanation is the bigger geographic and associated climatic

406 difference in the east-west gradient of the species, with low altitude coastal areas in the

407 west, and high mountains in the east. Temperature differences can have large effects

408 on the prevalence of pathogen populations as shown for wild plant-pathosystems

409 (Laine, 2008) and also on crops, pathogens show adaptation to different climates

410 (Mboup et al., 2012; Stefansson, McDonald \& Willi, 2013). The mountainous areas in

411 our study have particularly cold winters and relatively low mean temperatures in

412 summer, which could be detrimental for pathogen survival or slow its growth and thus

413 reduce pathogen pressure, which in turn might lead to loss of resistance in the plants. 
414 Our results show indeed that inclusion of climatic variables for "temperature in winter"

415 as well as "temperature in the wettest quarter" greatly improve our models and have a

416 significant effect on infection rate for both $A$. solani and $P$. infestans. The importance of

417 overwintering inoculum has previously been shown to be a main predictor for

418 Podosphaera plantaginis epidemics on Plantago lanceolata in the next growing season

419 (Soubeyrand et al., 2009). However, it must be noted that models that only incorporate

420 winter temperature or indeed any other single climatic variables effects did not show

421 any significance. This is in line with a between species comparison for wild potato

422 (Spooner et al., 2009) and might be related to the fact that some higher altitude

423 locations also have the highest annual precipitation rates. For example for $P$. infestans

424 a relative high humidity has large positive effects on successful sporulation (Harrison \&

425 Lowe, 1989), which could counter the negative temperature effects.

426

427 Our climate data were extracted from worldclim.org and might not provide the whole

428 picture. For example, precipitation data might be accurate, but do not take into account

429 a common sea-fog phenomenon that can be observed along the coast of Chile and

430 Peru (Cereceda \& Schemenauer, 1991; Schemenauer \& Cereceda, 1992). This fog

431 increases the local humidity for several hours up to several days in certain "fog basins".

432 Similarly, no data is available on any nearby streams, rivers or irrigation canals for any

433 of the populations. For some populations, a note is available for the state of the site at

434 the time of collection (e.g. "dry quebrada"), but it remains unknown whether these

435 features are constant or changed shortly before collection. 
437 The best fitted models incorporate five climatic and geographic variables. Adding more

438 variables did not improve the model, mainly due to the correlations between the

439 available climate data. The strongest effects were observed for combinations of

440 longitude and latitude together with climatic variables, indicating that one or two

441 variables alone do not determine pathogen resistance. The latitude effect, which can be

442 observed in the evolution of the species as a whole, seems to be less strong in our

443 analyses, where longitude plays a larger role. Overall, our results indicate that indeed S.

444 chilense populations show variations in pathogen resistance, which are possibly the

445 result of adaptations to local pathogen pressures. The mosaic-like structure of our

446 results indicates that these resistances are likely caused by a multitude of factors.

447 These findings are in line with several inter-species studies in wild potato, where no

448 correlation could be found between geographical location of the species and resistance

449 against $P$. infestans (Khiutti et al., 2015) or $A$. solani (Jansky, Simon \& Spooner, 2008).

450 To further unravel the combination of factors contributing to local variations, new

451 sampling excursions would be required, that not just collect plant and pathogen, but

452 also measure local geographic and climatic parameters.

454 Several mechanisms have been theoretically proposed to generate stable long term 455 polymorphism at host resistance and pathogen infectivity loci. Notably, many of those 456 are linked to the environmental heterogeneity across populations. Here we show that 1)

457 multiple environmental factors are required to improve the GLMM 2) infection rates

458 differ between populations and even within previously genetic groups and 3) S. chilense

459 populations show individual patterns in response to the three different pathogens. 
460 Therefore we conclude on 1) the existence of possible GxGxE interactions for given

461 host-pathogen interactions, 2) heterogeneity in disease incidence and prevalence

462 across habitats, and most interestingly 3) a likely geographic mosaic of exposure to

463 different pathogens. However, additional experiments with locally collected pathogens

464 are required to confirm these conclusions.

465 The presence-absence of different above- and below-ground pathogens on the same 466 plants may be a key component of wild systems generating scenarios such as co-

467 infection (Susi et al., 2015), cross-immunity or facilitation (Tack et al., 2015), with

468 consequences for the genomics of pathogens (McMullan et al., 2015). Our research did

469 not yet focus on any genetic differences underlying the variation in infection rates and

470 linking phenotype to genotype should be one of the follow-up projects. Identification of

471 the genes involved in these resistance variations could also help to identify which plant

472 defence mechanisms are affected between populations and if there are indeed

473 evolutionary differences between defence pathways in non-host resistance compared to

474 resistance variation within or in closely related species (Schulze-Lefert \& Panstruga,

475 2011; Stam et al., 2014). We have recently shown that targeted resequencing of genes

476 of interest (e.g. R-genes) can be a potent tool to calculate evolutionary parameters of

477 gene families of interest in wild tomato (Stam, Scheikl \& Tellier, 2016). Such

478 resequencing studies could thus help to pinpoint how molecular mechanisms are

479 affected by different pathogens as well as climatic variables.

\section{Conclusions}

482 Differences in pathogen disease resistance have been well described between many 
483 wild crop relatives. Here we presented a phenotypic study that shows large variation in 484 resistance against three common tomato pathogens between populations of the wild 485 tomato species $S$. chilense. We showed that there are clear differences between 486 individual populations. Using generalised linear mixed models, we show that this 487 variation does not follow a simple geographical cline, that multiple climatic factors are 488 needed to explain parts of the variation and that even within previously identified 489 genotype groups resistance properties can differ dramatically. Our study confirms a 490 mosaic pattern in resistance properties within one species and can form the starting 491 point for studies unravelling environmental effects on said properties as well as the 492 genetic and molecular mechanisms involved in plant-pathogen coevolution. 493 


\section{Acknowledgements}

495 We would like to thank Hannes Rief and Giulia Schiavoni for help with the scoring of the 496 infection assays, Hans Hausladen, Michael Heß and Regine Ditteman (TUM

497 Phytopathology) for providing the Alternaria strains and help with Fusarium isolation, 498 and Brian Harrower (The James Hutton Institute, Dundee, UK) for providing

499 Phytophthora and all reviewers and the editor for useful comments on the manuscript. 
500

501

\section{References}

Agrios GN. 2005. Plant Pathology. San Diego, CA: Elsevier.

Bates D., Mächler M., Bolker B., Walker S. 2015. Fitting Linear Mixed-Effects Models Using Ime4. Journal of Statistical Software 67:1-48. DOI: 10.18637/jss.v067.i01.

Becker OS code by RA., Minka ARWR version by RBE by TP., Deckmyn A. 2016. maps: Draw Geographical Maps.

Böndel KB., Lainer H., Nosenko T., Mboup M., Tellier A., Stephan W. 2015. NorthSouth Colonization Associated with Local Adaptation of the Wild Tomato Species Solanum chilense. Molecular Biology and Evolution:msv166. DOI: 10.1093/molbev/msv166.

Brown JKM., Tellier A. 2011. Plant-parasite coevolution: bridging the gap between genetics and ecology. Annual review of phytopathology 49:345-67. DOI: 10.1146/annurev-phyto-072910-095301.

Cereceda P., Schemenauer RS. 1991. The Occurrence of Fog in Chile. Journal of Applied Meteorology 30:1097-1105. DOI: 10.1175/15200450(1991)030<1097:TOOFIC>2.0.CO;2.

Chaerani R., Groenwold R., Stam P., Voorrips RE. 2007. Assessment of early blight (Alternaria solani. Journal of General Plant Pathology 73:96-103. DOI: 10.1007/s10327-006-0337-1.

Chaerani R., Voorrips RE. 2006. Tomato early blight (Alternaria solani): the pathogen, genetics, and breeding for resistance. Journal of General Plant Pathology 72:335-347. DOI: 10.1007/s10327-006-0299-3.

Dean R., Van Kan J a. L., Pretorius ZA., Hammond-Kosack KE., Di Pietro A., Spanu PD., Rudd JJ., Dickman M., Kahmann R., Ellis J., Foster GD. 2012. The Top 10 fungal pathogens in molecular plant pathology. Molecular Plant Pathology 13:414-430. DOI: 10.1111/j.1364-3703.2011.00783.x.

Fischer I., Camus-Kulandaivelu L., Allal F., Stephan W. 2011. Adaptation to drought in two wild tomato species: the evolution of the Asr gene family. New Phytologist 190:1032-1044. DOI: 10.1111/j.1469-8137.2011.03648.x.

Fischer I., Steige KA., Stephan W., Mboup M. 2013. Sequence Evolution and Expression Regulation of Stress-Responsive Genes in Natural Populations of Wild Tomato. PLOS ONE 8:e78182. DOI: 10.1371/journal.pone.0078182.

Forde SE., Thompson JN., Bohannan BJM. 2004. Adaptation varies through space and time in a coevolving host- parasitoid interaction. Nature 431:841-844.

Foster SJ., Park TH., Pel M., Brigneti G., Sliwka J., Jagger L., van der Vossen E., Jones JDG. 2009. Rpi-vnt1.1, a Tm-22 homolog from Solanum venturii, confers resistance to potato late blight. Mol Plant Microbe Interact 22:589-600.

Gandon S., Michalakis Y. 2002. Local adaptation, evolutionary potential and hostparasite coevolution: interactions between migration, mutation, population size and generation time. Journal of Evolutionary Biology 15:451-462.

Gavrilets S., Michalakis Y. 2008. Effects of Environmental Heterogeneity on VictimExploiter Coevolution. Evolution 62:3100-3116. DOI: 10.1111/j.15585646.2008.00513.x.

Griffiths PD., Scott JW. 2001. Inheritance and Linkage of Tomato Mottle Virus Resistance Genes Derived from Lycopersicon chilense Accession LA 1932. 
Journal of the American Society for Horticultural Science 126:462-467.

Harrison JG., Lowe R. 1989. Effects of humidity and air speed on sporulation of Phytophthora infestans on potato leaves. Plant Pathology 38:585-591. DOI: 10.1111/j.1365-3059.1989.tb01455.x.

Haverkort AJ., Struik PC., Visser RGF., Jacobsen E. 2009. Applied Biotechnology to Combat Late Blight in Potato Caused by Phytophthora Infestans. Potato Research 52:249-264. DOI: 10.1007/s11540-009-9136-3.

Hothorn T., Bretz F., Westfall P. 2008. Simultaneous Inference in General Parametric Models. Biometrical Journal 50:346-363.

Houterman PM., Cornelissen BJC., Rep M. 2008. Suppression of Plant Resistance Gene-Based Immunity by a Fungal Effector. PLoS Pathog 4:e1000061. DOI: 10.1371/journal.ppat.1000061.

Jansky SH., Simon R., Spooner DM. 2008. A test of taxonomic predictivity: Resistance to early blight in wild relatives of cultivated potato. Phytopathology 98:680-687. DOI: 10.1094/phyto-98-6-0680.

Ji Y., Scott JW., Hanson P., Graham E., Maxwell DP. 2007. Sources of Resistance, Inheritance, and Location of Genetic Loci Conferring Resistance to Members of the Tomato-Infecting Begomoviruses. In: Czosnek H ed. Tomato Yellow Leaf Curl Virus Disease. Springer Netherlands, 343-362.

Jousimo J., Tack AJM., Ovaskainen O., Mononen T., Susi H., Tollenaere C., Laine A-L. 2014. Ecological and evolutionary effects of fragmentation on infectious disease dynamics. Science 344:1289-1293. DOI: 10.1126/science.1253621.

Kamoun S., Furzer O., Jones JDG., Judelson HS., Ali GS., Dalio RJD., Roy SG., Schena L., Zambounis A., Panabières F., Cahill D., Ruocco M., Figueiredo A., Chen X-R., Hulvey J., Stam R., Lamour K., Gijzen M., Tyler BM., Grünwald NJ., Mukhtar MS., Tomé DFA., Tör M., Van Den Ackerveken G., McDowell J., Daayf F., Fry WE., Lindqvist-Kreuze H., Meijer HJG., Petre B., Ristaino J., Yoshida K., Birch PRJ., Govers F. 2015. The Top 10 oomycete pathogens in molecular plant pathology. Molecular Plant Pathology 16:413-434. DOI: 10.1111/mpp.12190.

Kavroulakis N., Ntougias S., Zervakis GI., Ehaliotis C., Haralampidis K., Papadopoulou KK. 2007. Role of ethylene in the protection of tomato plants against soil-borne fungal pathogens conferred by an endophytic Fusarium solani strain. J Exp Bot 58:3853-3864. DOI: erm230 [pii] 10.1093/jxb/erm230.

Khiutti A., Spooner DM., Jansky SH., Halterman DA. 2015. Testing Taxonomic Predictivity of Foliar and Tuber Resistance to Phytophthora infestans in Wild Relatives of Potato. Phytopathology 105:1198-1205. DOI: 10.1094/PHYTO-0215-0046-R.

Kumar S., Singh R., Kashyap PL., Srivastava AK. 2013. Rapid detection and quantification of Alternaria solani in tomato. Scientia Horticulturae 151:184-189. DOI: 10.1016/j.scienta.2012.12.026.

Laine AL. 2005. Spatial scale of local adaptation in a plant-pathogen metapopulation. Journal of Evolutionary Biology 18:930-938.

Laine A-L. 2006. Evolution of host resistance: looking for coevolutionary hotspots at small spatial scales. Proceedings. Biological Sciences / The Royal Society 273:267-273. DOI: $10.1098 / \mathrm{rspb} .2005 .3303$.

Laine A-L. 2008. Temperature-mediated patterns of local adaptation in a natural plant- 
pathogen metapopulation. Ecology Letters 11:327-337. DOI: 10.1111/j.14610248.2007.01146.x.

Leiminger JH., Auinger H-J., Wenig M., Bahnweg G., Hausladen H. 2016. Genetic variability among Alternaria solani isolates from potatoes in Southern Germany based on RAPD-profiles. Journal of Plant Diseases and Protection 120:164-172. DOI: 10.1007/BF03356470.

Lopez-Pascua LDC., Brockhurst MA., Buckling A. 2010. Antagonistic coevolution across productivity gradients: an experimental test of the effects of dispersal. Journal of Evolutionary Biology 23:207-211. DOI: 10.1111/j.1420-9101.2009.01877.x.

Ma L., Cornelissen BJC., Takken FLW. 2013. A nuclear localization for Avr2 from Fusarium oxysporum is required to activate the tomato resistance protein I-2. Frontiers in plant science 4:94. DOI: 10.3389/fpls.2013.00094.

Mboup M., Bahri B., Leconte M., De Vallavieille-Pope C., Kaltz O., Enjalbert J. 2012. Genetic structure and local adaptation of European wheat yellow rust populations: the role of temperature-specific adaptation. Evolutionary Applications 5:341-352. DOI: 10.1111/j.1752-4571.2011.00228.x.

McMullan M., Gardiner A., Bailey K., Kemen E., Ward BJ., Cevik V., Robert-Seilaniantz A., Schultz-Larsen T., Balmuth A., Holub E., van Oosterhout C., Jones JDG. 2015. Evidence for suppression of immunity as a driver for genomic introgressions and host range expansion in races of Albugo candida, a generalist parasite. eLife 4. DOI: 10.7554/eLife.04550.

Michielse CB., Rep M. 2009. Pathogen profile update: Fusarium oxysporum. Molecular Plant Pathology 10:311-324. DOI: 10.1111/j.1364-3703.2009.00538.x.

Moreno-Gamez S., Stephan W., Tellier A. 2013. Effect of disease prevalence and spatial heterogeneity on polymorphism maintenance in host-parasite interactions. Plant Pathology 62:133-141.

Nosenko T., Böndel KB., Kumpfmüller G., Stephan W. 2016. Adaptation to low temperatures in the wild tomato species Solanum chilense. Molecular Ecology 25:2853-2869. DOI: 10.1111/mec.13637.

Nowicki M., Foolad MR., Nowakowska M., Kozik EU. 2011. Potato and Tomato Late Blight Caused by Phytophthora infestans: An Overview of Pathology and Resistance Breeding. Plant Disease 96:4-17. DOI: 10.1094/PDIS-05-11-0458.

Peralta IE., Spooner DM., Knapp S. 2008. The taxonomy of tomatoes: a revision of wild tomatoes (Solanum section Lycopersicon) and their outgroup relatives in sections Juglandifolium and Lycopersicoides. Systematic Botany Monographs 84:1-186.

Perez WG., Gamboa JS., Falcon YV., Coca M., Raymundo RM., Nelson RJ. 2001. Genetic Structure of Peruvian Populations of Phytophthora infestans. Phytopathology 91:956-965. DOI: 10.1094/PHYTO.2001.91.10.956.

Rose LE., Grzeskowiak L., Hörger AC., Groth M., Stephan W. 2011. Targets of selection in a disease resistance network in wild tomatoes. Molecular Plant Pathology 12:921-927. DOI: 10.1111/j.1364-3703.2011.00720.x.

Rose LE., Langley CH., Bernal AJ., Michelmore RW. 2005. Natural Variation in the Pto Pathogen Resistance Gene Within Species of Wild Tomato (Lycopersicon). I. Functional Analysis of Pto Alleles. Genetics 171:345-357. DOI: 10.1534/genetics.104.039339. 
Rose LE., Michelmore RW., Langley CH. 2007. Natural variation in the Pto disease resistance gene within species of wild tomato (Lycopersicon). II. Population genetics of Pto. Genetics 175:1307-1319.

Salvaudon L., Giraud T., Shykoff JA. 2008. Genetic diversity in natural populations: a fundamental component of plant-microbe interactions. Current Opinion in Plant Biology 11:135-143. DOI: 10.1016/j.pbi.2008.02.002.

Schemenauer R., Cereceda P. 1992. Meteorological conditions at a coastal fog collection site in Peru. Atmósfera 6.

Schulze-Lefert P., Panstruga R. 2011. A molecular evolutionary concept connecting nonhost resistance, pathogen host range, and pathogen speciation. Trends Plant Sci 16:117-125.

Song W., Ma X., Tan H., Zhou J. 2011. Abscisic acid enhances resistance to Alternaria solani in tomato seedlings. Plant physiology and biochemistry: PPB / Société française de physiologie végétale 49:693-700. DOI: 10.1016/j.plaphy.2011.03.018.

Soubeyrand S., Laine A -L., Hanski I., Penttinen A. 2009. Spatiotemporal Structure of Host-Pathogen Interactions in a Metapopulation. The American Naturalist 174:308-320. DOI: 10.1086/603624.

Spooner DM., Jansky SH., Simon R., Spooner DM., Jansky SH. 2009. Tests of Taxonomic and Biogeographic Predictivity: Resistance to Disease and Insect Pests in Wild Relatives of Cultivated Potato

Städler T., Arunyawat U., Stephan W. 2008. Population genetics of speciation in two closely related wild tomatoes (Solanum section Lycopersicon). Genetics 178:339-50. DOI: 10.1534/genetics.107.081810.

Städler T., Roselius K., Stephan W. 2005. Genealogical footprints of speciation processes in wild tomatoes: demography and evidence for historical gene flow. Evolution; International Journal of Organic Evolution 59:1268-1279.

Stam R., Mantelin S., McLellan H., Thilliez G. 2014. The role of effectors in nonhost resistance to filamentous plant pathogens. Frontiers in Plant Science 5:582. DOI: 10.3389/fpls.2014.00582.

Stam R., Scheikl D., Tellier A. 2016. Pooled Enrichment Sequencing Identifies Diversity and Evolutionary Pressures at NLR Resistance Genes within a Wild Tomato Population. Genome Biology and Evolution 8:1501-1515. DOI: 10.1093/gbe/evw094.

Stefansson TS., McDonald BA., Willi Y. 2013. Local adaptation and evolutionary potential along a temperature gradient in the fungal pathogen Rhynchosporium commune. Evolutionary Applications 6:524-534. DOI: 10.1111/eva.12039.

Susi H., Barrès B., Vale PF., Laine A-L. 2015. Co-infection alters population dynamics of infectious disease. Nature Communications 6:5975. DOI: 10.1038/ncomms6975.

Tabaeizadeh Z., Agharbaoui Z., Harrak H., Poysa V. 1999. Transgenic tomato plants expressing a Lycopersicon chilense gene demonstrate improved resistance to Verticillium dahliae race 2. Plant Cell Reports 19:197-202. DOI: 10.1007/s002990050733.

Tack AJM., Laine A-L., Burdon JJ., Bissett A., Thrall PH. 2015. Below-ground abiotic and biotic heterogeneity shapes above-ground infection outcomes and spatial 
divergence in a host-parasite interaction. New Phytologist 207:1159-1169. DOI: $10.1111 / \mathrm{nph} .13408$.

Tellier A., Brown JKM. 2007. Stability of genetic polymorphism in host-parasite interactions. Proceedings. Biological sciences / The Royal Society 274:809-17. DOI: $10.1098 / \mathrm{rspb} .2006 .0281$.

Tellier A., Brown JKM. 2009. The Influence of Perenniality and Seed Banks on Polymorphism in Plant-Parasite Interactions. The American Naturalist 174:769_ 779.

Tellier A., Brown JKM. 2011. Spatial heterogeneity, frequency-dependent selection and polymorphism in host-parasite interactions. BMC Evolutionary Biology 11:319.

Tellier A., Fischer I., Merino C., Xia H., Camus-Kulandaivelu L., Städler T., Stephan W. 2011. Fitness effects of derived deleterious mutations in four closely related wild tomato species with spatial structure. Heredity 107:189-199.

Thompson JN. 2005. The Geographic Mosaic of Coevolution. Chicago: University of Chicago Press.

Thrall PH., Burdon JJ. 2002. Evolution of gene-for-gene systems in metapopulations: the effect of spatial scale of host and pathogen dispersal. Plant Pathology 51:169-184.

Thrall PH., Burdon JJ. 2003. Evolution of virulence in a plant host-pathogen metapopulation. Science (New York, N.Y.) 299:1735-1737. DOI: 10.1126/science.1080070.

Thrall PH., Burdon JJ., Bever JD. 2002. Local adaptation in the Linum marginaleMelampsora lini host-pathogen interaction. Evolution; International Journal of Organic Evolution 56:1340-1351.

Thrall PH., Burdon JJ., Bock CH. 2001. Short-term epidemic dynamics in the Cakile maritima-Alternaria brassicicola host-pathogen association. Journal of Ecology 89:723-735.

Thrall PH., Burdon JJ., Young A. 2001. Variation in resistance and virulence among demes of a plant host-pathogen metapopulation. Journal of Ecology 89:736748.

Vargas AM., Ocampo LMQ., Céspedes MC., Carreño N., González A., Rojas A., Zuluaga AP., Myers K., Fry WE., Jiménez P., Bernal AJ., Restrepo S. 2008. Characterization of Phytophthora infestans Populations in Colombia: First Report of the A2 Mating Type. Phytopathology 99:82-88. DOI: 10.1094/PHYTO-99-10082.

Verlaan MG., Hutton SF., Ibrahem RM., Kormelink R., Visser RGF., Scott JW., Edwards JD., Bai Y. 2013. The Tomato Yellow Leaf Curl Virus Resistance Genes Ty-1 and Ty-3 Are Allelic and Code for DFDGD-Class RNA-Dependent RNA Polymerases. PLOS Genet 9:e1003399. DOI: 10.1371/journal.pgen.1003399.

Vogwill T., Fenton A., Buckling A., Hochberg ME., Brockhurst MA. 2009. Source Populations Act as Coevolutionary Pacemakers in Experimental Selection Mosaics Containing Hotspots and Coldspots. The American Naturalist 173:E171-E176. DOI: 10.1086/597374.

Warnes GR., Bolker B., Bonebakker L., Gentleman R., Liaw WHA., Lumley T., Maechler M., Magnusson A., Moeller S., Schwartz M., Venables B. 2016. gplots: Various $R$ Programming Tools for Plotting Data. 
Wickham H. 2009. ggplot2: Elegant Graphics for Data Analysis. Springer-Verlag New York.

502 


\section{Figure 1 (on next page)}

S. chilense populations and phenotypic observations
A) A map showing the populations used in this study, belonging to the central (red), southern mountainous (blue) or southern coastal (green) region. The geographic range of whole species is depicted in the background (grey dots). B) The phenotypic observations after infection range from no visible symptoms (first row) and small black necrotic lesions resembling the Hypersensitive Response (HR, second row), both scored as 'not infected', to intermediate and strong infection (third and fourth row), both scored as 'infected'. In the columns from left to right: infection with Alternaria, Fusarium and Phytophthora. We could not observe HR in the Alternaria infections. C) Experimental set-up. Detached leaves were randomised for each population (P\#) and spread over various boxes. Each leaflet was drop inoculated and scored. 


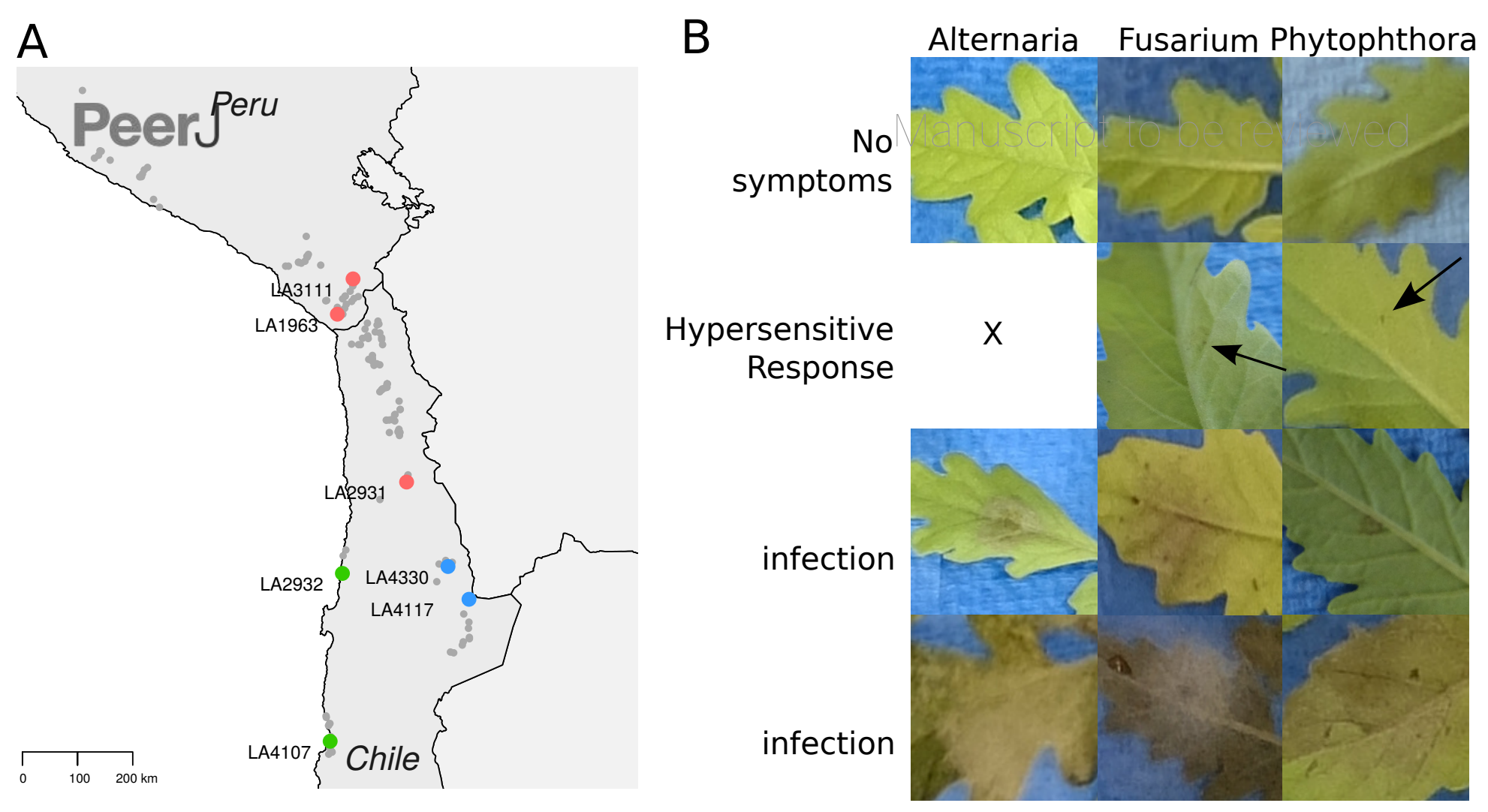

C

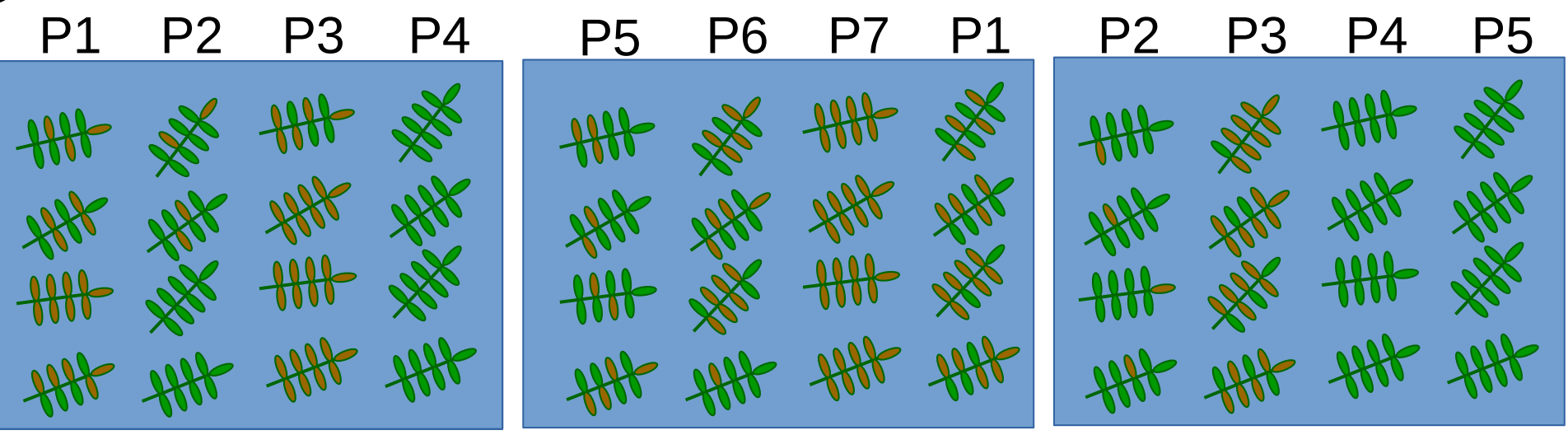

$\begin{array}{llllllll}\text { P6 } & \text { P7 } & \text { P1 } & \text { P2 } & \text { P3 } & \text { P4 } & \text { P5 } & \text { P6 }\end{array}$

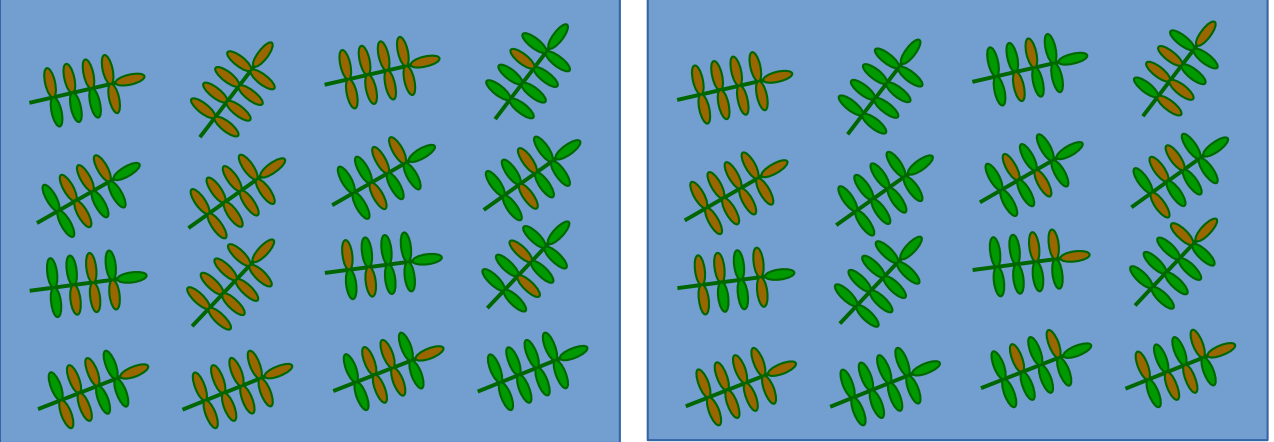

Etc. 
Figure 2 (on next page)

Infected leaf fraction for different S. chilense populations

The boxplots show the median and 1st and 3rd quartile of the infected fractions per leaf for A) Alternaria, B) Fusarium and C) Phytophthora. The black dots represent the mean value for the infections. The $Y$ axis ranges from 0 (no infected leaflets on a leaf) to 1 (all leaflets show infection). On the $\mathrm{X}$ axis, each population is represented. The colours correspond to the geographic regions as depicted in figure 1. 


$$
\text { Alternaria infected leaves }
$$

Fusarium infected leaves

Phytophthora infected leaves

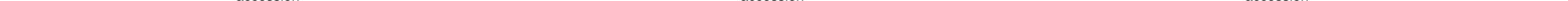


Figure 3 (on next page)

Populations with significant different infected fractions

Graph depicting whether a pairwise difference shows a significant result for Alternaria solani (left column), Fusarium sp. (middle column) and Phytophthera infestans (right column). Each row represents a pairwise comparison. Green cells represent a significant difference $(p<$ 0.001 after multiple testing correction) and the numbers represent the estimated effect, with negative numbers indicating that the population mentioned on the left is less resistant than the one on the right. 


$\begin{array}{cccc}\text { Alternaria } & \text { Fusarium } & \text { Phytophthora } & \\ -0.55183 & 0.10738 & -0.26040 & \text { LA1963 - LA2931 } \\ -0.87557 & -0.78253 & -0.73009 & \text { LA1963 - LA2932 } \\ 0.29545 & -1.11537 & 0.26290 & \text { LA1963 - LA3111 } \\ -0.150 & 0.71985 & -0.26015 & \text { LA1963 - LA4107 } \\ -0.04-1.50 & 0.88139 & -0.42327 & \text { LA1963 - LA4117 } \\ -1.37044 & 0.02266 & -1.23225 & \text { LA1963 - LA4330 } \\ -0.32373 & -0.88991 & -0.46969 & \text { LA2931 - LA2932 } \\ 0.84728 & -1.22275 & 0.52330 & \text { LA2931 - LA3111 } \\ -0.29967 & 0.61247 & 0.00025 & \text { LA2931 - LA4107 } \\ 0.08695 & 0.77401 & 0.16287 & \text { LA2931 - LA4117 } \\ -0.81860 & -0.08472 & -0.97185 & \text { LA2931 - LA4330 } \\ 1.17102 & -0.33285 & 0.99300 & \text { LA2932 - LA3111 } \\ 0.02407 & 1.50237 & 0.46994 & \text { LA2932 - LA4107 } \\ 0.41069 & 1.66391 & 0.30681 & \text { LA2932 - LA4117 } \\ 0.49487 & 0.80518 & -0.50215 & \text { LA2932 - LA4330 } \\ -1.14695 & 1.83522 & -0.52305 & \text { LA3111 - LA4107 } \\ -0.76033 & 1.99676 & -0.68618 & \text { LA3111 - LA4117 } \\ -1.66588 & 1.13803 & -1.49516 & \text { LA3111 - LA4330 } \\ 0.38662 & 0.16154 & -0.16312 & \text { LA4107 - LA4117 } \\ -0.51894 & -0.69719 & -0.97210 & \text { LA4107 - LA4330 } \\ -0.90556 & -0.85873 & -0.80897 & \text { LA4117 - LA4330 }\end{array}$




\section{Table $\mathbf{1}$ (on next page)}

Table 1

Summary of GLMM results. AIC is a measure of relative quality of the model, with a lower AIC (within one species) indicating a better model. AICs in bold represent models that are significant $(p<0.001)$. TempA denotes the temperature in the wettest quarter, TempB in the coldest quarter and TempC the annual mean temperature. 


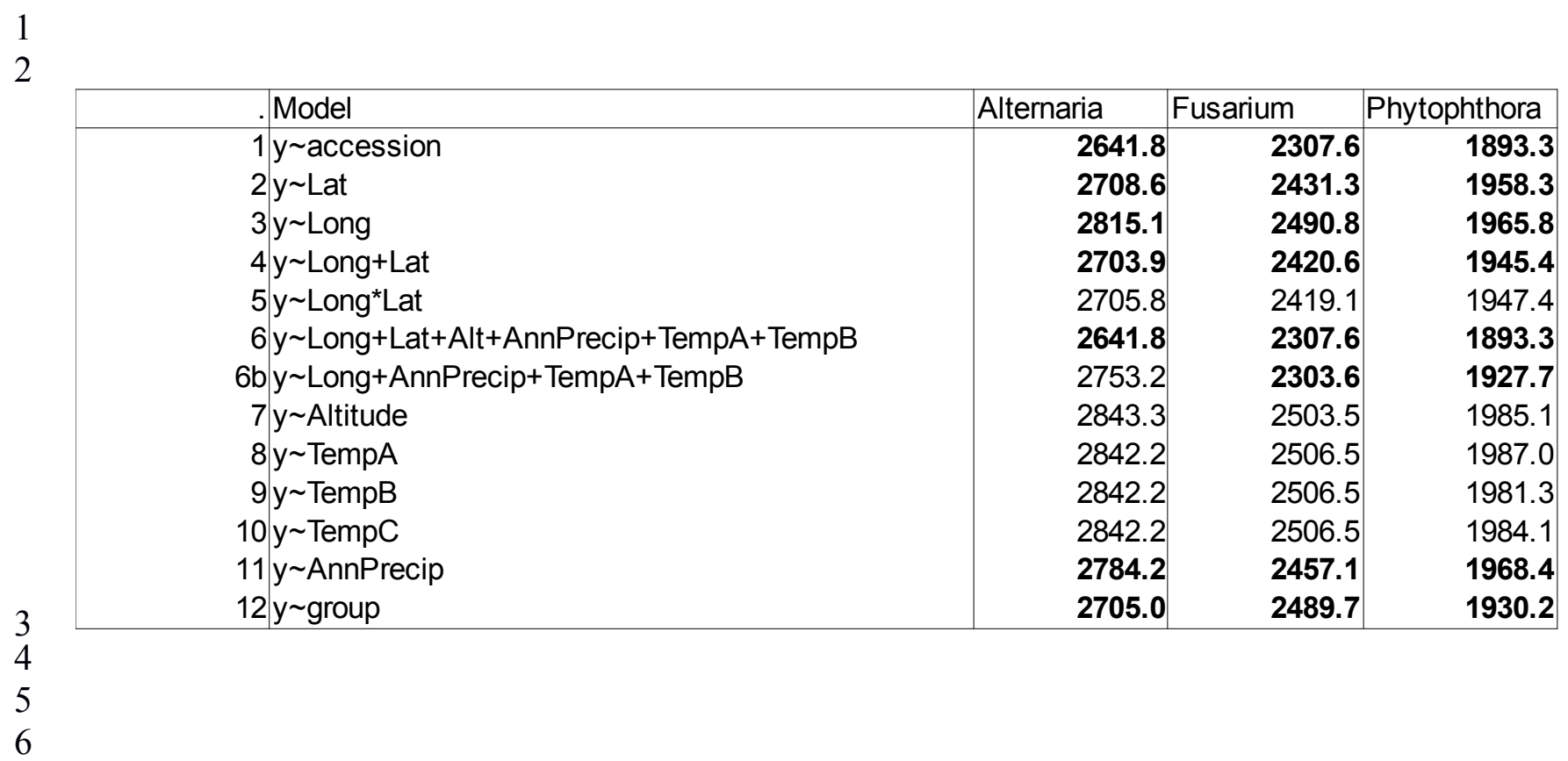




\section{Table 2 (on next page)}

Effects and significance of environmental variables

Esitmated size of the effect and the significance for all variables used in model 6 (Table 1). Pvalues in bold are deemed significant. TempA denotes the temperature in the wettest quarter, TempB in the coldest quarter 
1

\begin{tabular}{|c|c|c|c|c|c|c|}
\hline Variable & $\begin{array}{l}\text { Alternaria } \\
\text { Effect Estimate }\end{array}$ & P-value & $\begin{array}{l}\text { Fusarium } \\
\text { Effect Estimate }\end{array}$ & P-value & $\begin{array}{l}\text { Phytophthora } \\
\text { Effect Estimate }\end{array}$ & P-value \\
\hline Latitude & -0.5 & $<0.001$ & -0.1 & 0.8 & -0.3 & $<0.001$ \\
\hline Longitude & 17.4 & $<0.001$ & 7.9 & 0.007 & 17.3 & $<0.001$ \\
\hline Altitude & -7.4 & $<0.001$ & 0.0 & 0.99 & -6.5 & $<0.001$ \\
\hline Precipitation & 9.1 & $<0.001$ & 3.8 & 0.02 & 8.3 & $<0.001$ \\
\hline TempA & 3.2 & $<0.001$ & 1.5 & 0.004 & 3.1 & $<0.001$ \\
\hline TempB & 10.2 & $<0.001$ & 7.8 & $<0.001$ & 10.6 & $<0.001$ \\
\hline
\end{tabular}

3 